\section{TEACHING CHEMISTRY}

THE Royal Institute of Chemistry has a splendid record in education. For several years it has worked hard on schemes to introduce modern ideas to teachers of chemistry in the schools. A year ago it broke new ground with a series of conferences for teachers, and if these were less successful than more permanent arrangements for teacher training would have been, the Institute is not the organization to blame for that. A measure of the Institute's educational ambitions is the fact that it is trying to raise $£ 100,000$ to finance a number of educational projects. One of the first things to be attempted is a study of the relationship between undergraduate and postgraduate courses at British universities, and this will provide an important part of the background to a conference on university education in chemistry due to be held in Manchester next January. That promises to be a valuable exercise.

With all this evidence of virtue, it is surprising that the Institute has so far done very little to remove the anomalous impediments to the transfer of bright young men and women from British schools to departments of chemistry at the universities. These are peculiarly British problems, and consequences of the bizarre practice of specialization in the schools. Like many other organizations, the Institute has been worried about them for some time. The most alarming symptom of what is wrong is the stagnation of so many of those who leave school at eighteen with a qualification in chemistry. In circumstances in which senior pupils must usually specialize in three subjects, chemistry has suffered more than physics, biology and mathematics from the attractiveness of newer studies such as economics. Yet British universities remain curiously inflexible in what they ask of intending entrants to chemistry departments. At most British universities, those with their cyes on a career in chemistry must present themselves with examination qualifications in mathematics, physics and chemistry. One immediate absurdity is that only a tiny handful of British graduates in chemistry have ever studied biology except at an elementary level. A more insidious evil is that young people inevitably suppose the rigidity of the regulations for entering a chemistry department to be a sign that chemistry itself is a kind of straitjacket. By requiring that young people wishing to take up chemistry at university should so resolve at sixteen, the same rigidity probably ensures that many potential chemists finish up in other disciplines.

These tendencies are probably a sufficient explanation of why chemistry has been lagging behind other scientific studies in the interchange between British schools and universities. All the Institute's work on the in-service training of teachers, and its willingness to spend liberally from its limited resources, can only be a palliative. It is like trying to cure measles by painting out the spots. Sooner or later there will have to be a direct attack on the problem of the demands made by the universities on would-be entrants to chemistry departments. As things are, the chemists. are outdone in conservatism only by the mathematicians. The universities will have to recognize that they cannot rely indefinitely on the schools to supply them with stereotyped young chemists. If the altermative should be a fourth year at university, the chemists should not shrink from saying so.

\section{SOBER SOCIAL SCIENCE}

THose who may with justice have been afraid that the creation of the Social Science Research Council would be a device for subsidizing and perpetuating secondrate academic work at the universities should now be comforted. The first list of grants awarded by the Council is as respectable as anybody could ask. Altogether the Council has allotted $£ 150,000$ to eighteen projects. The recipients are as distinguished as they are well known. There is some straightforward social anthropology in Western Nepal and a study of kinship and support in pregnancy. Economics does well, and the study of the making of decisions in public enterprises which Prof. R. L. Meek is undertaking should be useful as well as interesting. The Council has done well to find a project on the development of cognitive skills in children, for too little work of that kind is being carried out in Britain, and there is a useful list of projects in what may properly be called industrial anthropology-the consequences of redundancy among the workers in a factory in South Wales, for example. It is particularly welcome that the Council should be supporting a study of the experiment at the Fairfields Shipyard in Glasgow whose ownership has been transferred to the British Government and certain trade unions.

Why, then, have academies been afraid of what the Social Science Research Council would attempt? And can they now relax, putting their trust in Dr. Michael Young and his committee? The difficulty, of course, is to know what is meant by social science. The several recent authorities on the subject, and particularly the Heyworth Committee, have been deplorably vague, with the result that too much attention has been drawn to pronouncements tending to suggest that any ill-considered set of concepts can be turned into a piece of science by a sufficient array of numerical information and a few applications of the chi-squared test. More seriously, except in fields such as economics, it is still uncommonly difficult to extract general conclusions from the kinds of studies to which social scientists appear prone. Having asked the wives of miners in Yorkshire how they spend their housekeeping money, there is often nothing to do but to put the same questions to miners' wives in Nottingham. Avoiding repetitious projects of this kind will be a constant headache. The temptation to lower standards will be great. The Social Science Research Council has begun well, but it will be helped by being watched closely. 